\title{
A Farewell to Arms: research on the disposal of a former military system in Friuli Venezia Giulia
}

\author{
A. Santarossa \\ University IUAV of Venice, Italy
}

\begin{abstract}
The ideological clash opposing Eastern and Western Europe from the beginning of the $20^{\text {th }}$ century till the end of the 80 s resulted in the north-east of Italy being one of the heaviest military structures of the world. A dense grid of bunkers, military sites, barracks, explosives sites, training and aviation camps, spread throughout the country, made a reality the idea of a landscape as a strategic scenario. Friuli Venezia Giulia, the region more affected by this system, has seen $50 \%$ of its area influenced by easement for military purposes and counts today $102 \mathrm{~km}^{2}$ of military zones.

After 1989, wide parts of its region, in urban, agricultural or natural context historically separated from everyday life and its use - suddenly lost their function and moved towards a state of neglect and degradation. No one knows how many of such sites there are.

With the independent research A Farewell to Arms, an extensive survey was carried out mapping 210 former sites; probably more than 200 are still in review, which theoretically means a military site every $15 \mathrm{~km}$. We are facing the collapse of an entire system that has influenced for several years the whole region and further afield.

Now we are developing different models of reconversion that are based on a precise hypothesis: is it possible to reconvert a former military network into a new one? Starting not from a "site by site" but from a "system by system" approach that takes into account the position and the geographical and infrastructural values of the former sites, the models of reconversion investigate the possibility to reinterpret an area through its former military heritage.

Keywords: barracks, military disposal, military site, military system analysis, reconversion scenarios.
\end{abstract}




\section{Introduction}

For the man in the street, a wall, some barbed wire and some visible portion of a roof represent a barrack. What happens beyond that wall is unknown, and therefore life flows around it without influencing it directly. A whole area grows and develops over the years without taking into account this external body: this is a very particular urban phenomenon, a direct result of the need for control and secrecy inherent in the military system. As strategist Jean Charles [1] said, the more effective the militarisation of an area the less visible it is, and in urban terms the military function is aptly defined as separate function. Paradoxically, it is only when it ceases to exist that its traces, falling into disuse, become apparent.

The presence of military bases leads to establishing real internal boundaries beyond which the judgment of the city, its needs and will have had to stop. This is why, when a military base is abandoned, a complex phenomenon occurs: it is a forgotten part of the city that comes back to light, a new body that suddenly appears and threatens to upset the balance of the whole organism. It is like discovering a new room in your own house after living there for decades, a room that sometimes can reveal a size almost equal to that of the entire house.

The problem is even more complex when it is not only part of a city to be disposed of, but a whole area, and not a continuous, enclosed and definite part, but rather a constellation of points scattered around the entire region.

This is the case in Italy of Friuli Venezia Giulia.

\section{The case of Friuli Venezia Giulia: a strategic landscape}

An Italian border region, but especially the border region of the western world: these are the assumptions that led to Friuli Venezia Giulia becoming the most militarised region of Italy and Europe. The succession of two world wars and the Cold War were the basis of a process of defence structuring of the area, which having to respond to conflicts and geographies that differ greatly from each other - has never experienced the reuse of the existing, but its continued implementation. To the infrastructures of the First World War those from the Second were added, which were laid out according to different borders and hence other parts of the region. Lastly, with the Cold War, an underground and latent war introduced new ways of combat and defence and the entire region became a battlefield.

An investigation by the Ministry of Defence [2] has estimated that over 60 years an area of $103 \mathrm{~km}^{2}$ (1.3\% of the region) was occupied by military sites, while nearly $50 \%$ of the region was subject to subsequent easement for military purposes. A dense network of barracks, explosives sites, training and aviation camps developed on the upper Veneto and in greater part of Friuli Venezia Giulia with the sole purpose of military strategy. Cities, towns, fields, valleys, mountains, rivers and the sea were used as elements of a map: the landscape of Friuli Venezia Giulia was transformed into a strategic landscape. 


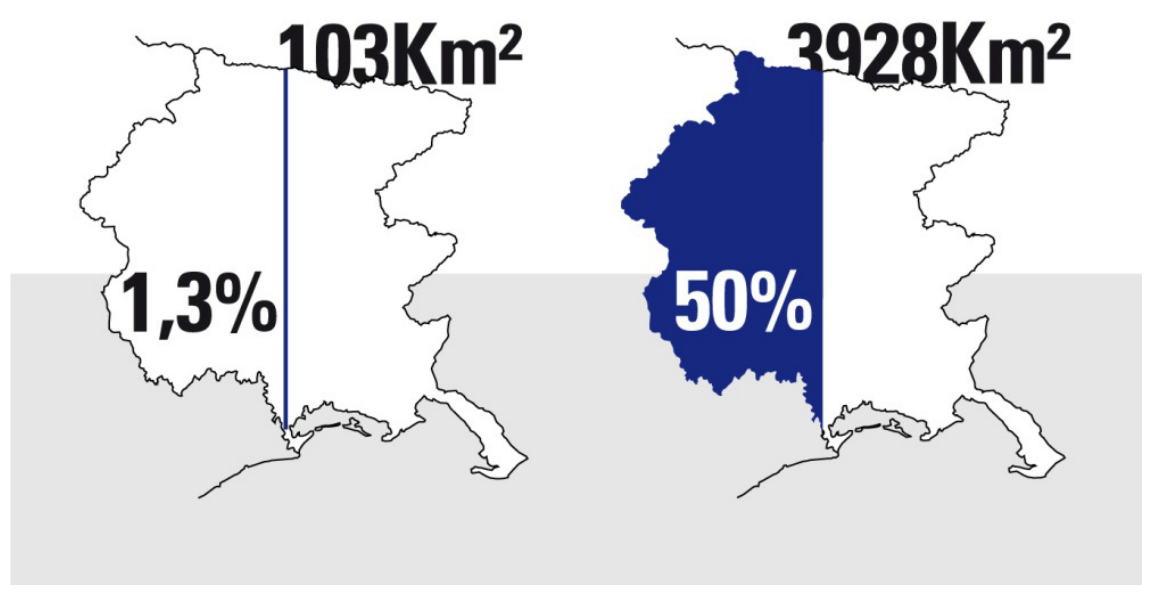

Figure 1: 103 square kilometres of military sites correspond to a large military base 1 kilometre large across the whole region. The easement for military purposes includes almost 4,000 square kilometres of the area. Drawing (C) Corde Architetti.

For nearly 50 years, Friuli Venezia Giulia was for Italians the place where one would go for military service. In the last 20 years this is no longer the case. The fall of the Berlin Wall, marking the crisis of strategic confrontation between Western and Eastern Europe, led the military system, up to that moment developed and maintained, to quickly lose its meaning. At the same time the defence system changed, mass armies were replaced by professional armies, which required less space, new types of building and a different deployment in the area. The demise of the Italian military system thus began, which has taken unique proportions in the Friuli Venezia Giulia region compared to the rest of Europe.

\section{Mapping the phenomenon}

In 2006 an Italian national newspaper [3] published and quoted, thanks to a leak, a study by the Military Prosecution of Padua from 2001, which reported for Friuli Venezia Giulia the incredible number of 407 abandoned military sites. This is a huge number because it translates as an army barrack almost every $15 \mathrm{~km}$. Driven by curiosity to know more about this phenomenon, in 2008 we started to gather information on the actual size of the cessation of military buildings in Friuli Venezia Giulia. The result was shocking: no one in the public administration was able to provide even the slightest data as to how many of the sites were abandoned and their state of preservation. Attempting to access this information through the Italian army was a failure, the reason for refusal being national security issues. 


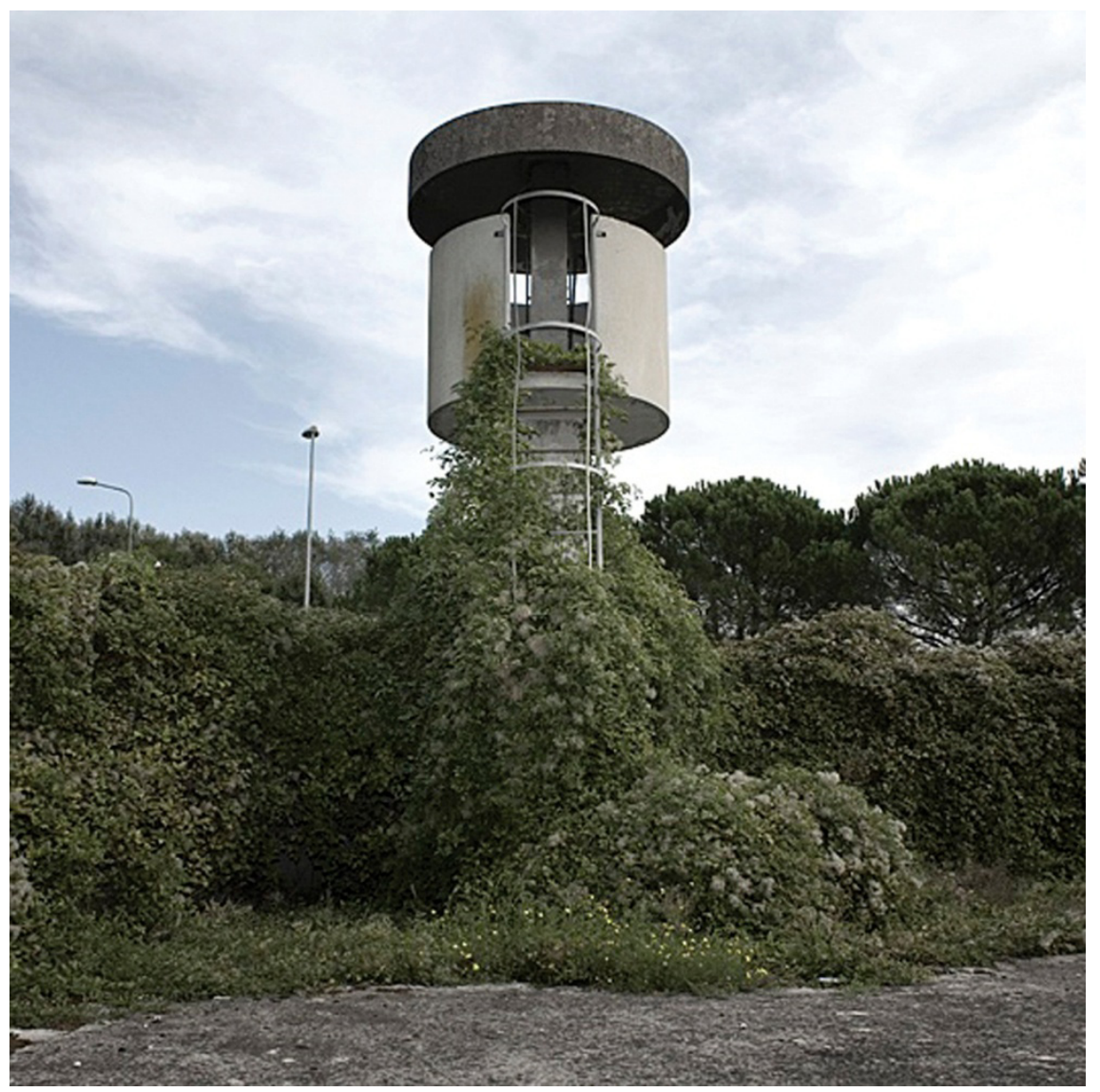

Figure 2: $\quad$ Most of the sites lie in a state of abandonment. Photo CFabrizio Giraldi.

We therefore decided to pursue independently a mapping of abandoned military sites, starting from the two legislative decrees of 2001 [4] and 2007 [5] that transferred free of charge from the Military property to public administrations about 168 sites, but of which none had ever drawn a map or a classification before. This mapping, supported by indications of ex-military and direct inspections, on 31.12.2010 was discontinued for economic reasons, after surveying about 210 abandoned military sites of various types and sizes.

\section{The classification}

Drawing up a general plan and classifying these sites are essential tools for knowledge and to understand and deeply analyse a phenomenon of such importance. 
The classification resulted in the identification of 6 fairly consistent groups:

1. Military buildings;

2. Barracks and adjoining areas;

3. Explosives site and ammunition depots;

4. Infrastructures;

5. Fortifications;

6. Training areas and state property.

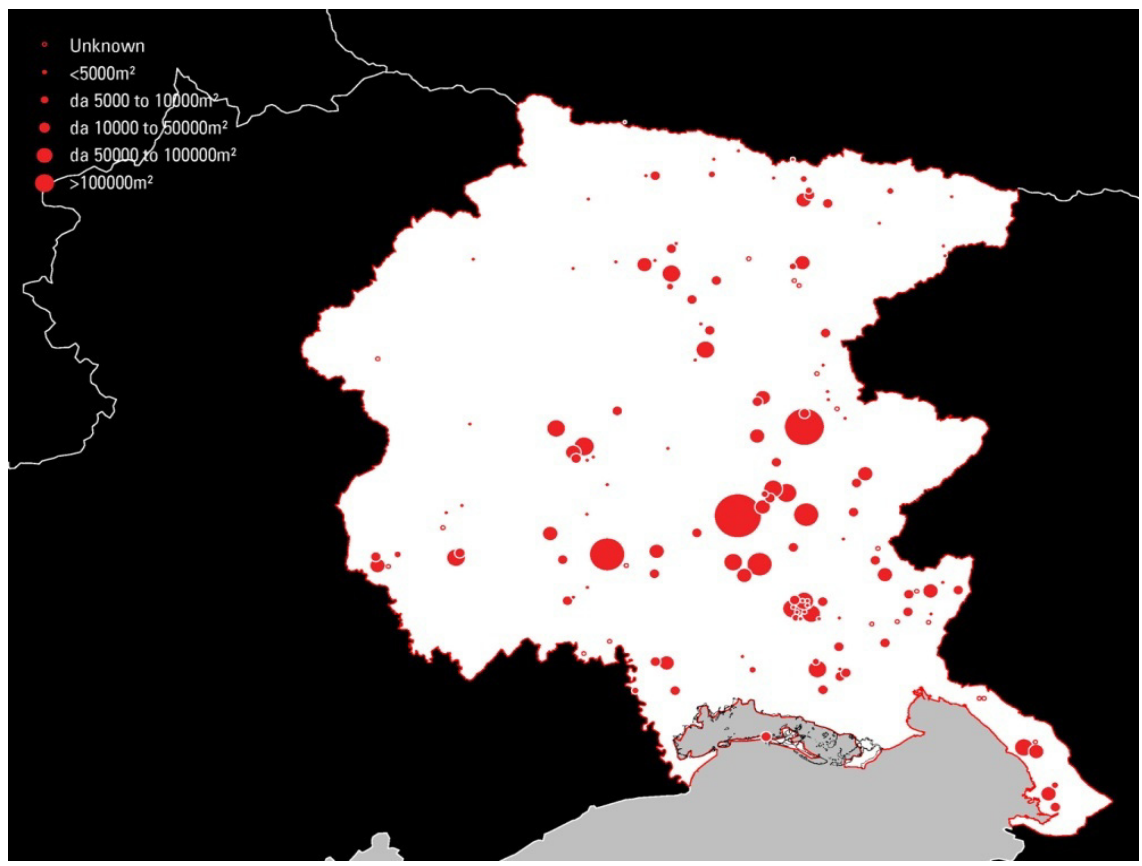

Figure 3: Classification of the sites according to surface. Drawing (C)orde Architetti.

Then we proceeded to split the region into quadrants of $25 \mathrm{~km}$, preparing for each of them a record of the present sites, highlighting their geographical location, the characteristics of the specific area (type, abandoned surface and its permeability, presence or absence of buildings) and of the place where it is and it necessarily relates to (the surface of the municipality in which it is located, the number of inhabitants living there, etc.).

\section{Analysis of a system}

The plan of the abandoned sites evokes an image full of consideration: these scattered points - and one should remember that in all probability the actual ones are almost double the size - represent more than a series of areas in 


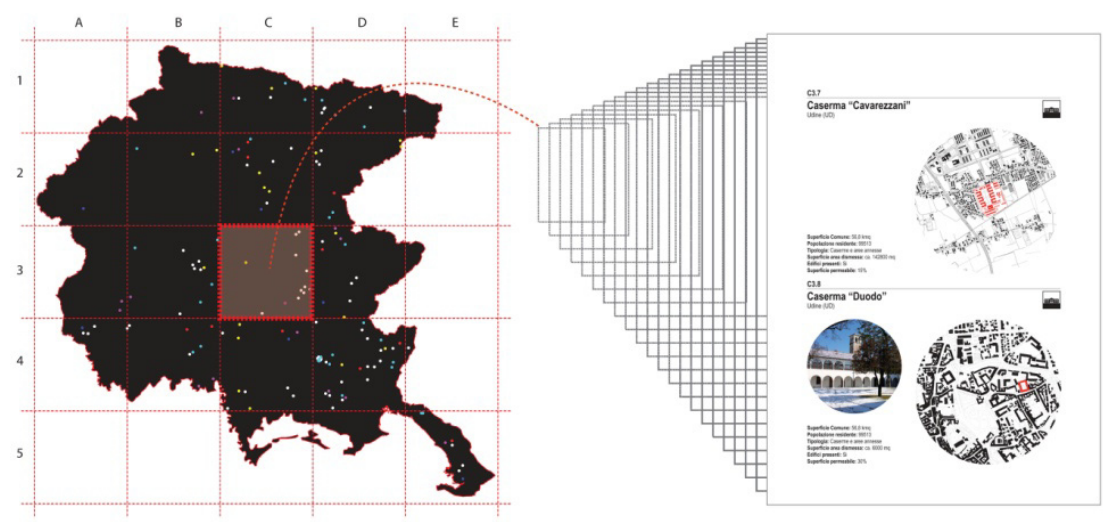

Figure 4: $\quad$ Example of indexing. Drawing (C) Corde Architetti.

abandonment. This is not a simple disposal of points scattered around that affect some small towns, but it is a total collapse of a system that for decades has affected, both positively and negatively, the whole region. A system of points connected to each other that worked together or were complementary and that belonged to a strategic plan of defence of the borders and the area.

A question therefore arises: how is a military system influenced by the area where it is located and how does it affect its structure? The analysis we carried out compares the abandoned military system to the classical maps (municipal boundaries, road system, built area, topography, hydrography, etc.). Examining the network of barracks this way sheds an unexpected light on the phenomenon of abandoned sites and on the relationships between sites and between the latter and the surrounding land. For instance, the proximity to a river or the fact of being inside a protected area or near an infrastructure axis may suddenly turn an issue into an opportunity. In this large-scale framework abandoned military sites are no longer scattered points that need conversion, but can also become a system to envision scenarios of reconversion and development.

\section{Reconversion scenarios}

Is it possible to use the organisation and strategic planning characteristics that led to building military sites in certain places for completely different purposes? This is the pillar of the project A Farewell to Arms. To further clarify it let's make a simple example: a military system can be compared to an electrical system of a house - it exists but it cannot be seen except for some sporadic points on the walls. If this electrical system stops working, what can be done? It has to be removed completely by setting up a new one, but breaking all the walls in the house or trying to use the existing layout, the electrical panels and leaving some of the wire still intact?

We believe that, due to its extension, in this large-scale framework, the disuse in Friuli Venezia Giulia can represent an opportunity to reconsider the future of 
the whole region, creating one of its the possible development axes. Starting from the issues in the region (the economic growth, the housing emergency and energy sustainability) we are analysing to what extent the abandoned military system can be reorganised to such new needs, while taking advantage of its intrinsic characteristics.

On this basis, we are working towards the development of 3 scenarios and credible hypotheses of reconversion:

1 Tourism scenario;

2 Energy scenario;

3 Social-housing scenario.

They are not alternative hypotheses but are complementary to each other. The idea is that a site can fall into one or more hypotheses, subsequently exposing reconversion to more channels of financing, profitability and management, reaching a functional complexity that can be easily integrated to the context.

Describing every single scenario would require a lot of time. For that reason we will just describe the methodology of each one.

\subsection{Tourism scenario}

The military and tourist world have often taken into consideration places and landscapes in a similar way. As an example it could be considered:

1 The need to control/see that they have in common (the choice of a place as an ideal point to control a valley also converts it into a panoramic spot of great value).

2 The need of blocking access to an area has often led to the slow transformation of wide military areas into biotopes of great value and high international interest, opening the doors to their use as natural sights. (It should be noted that the large easements for military purposes, constraining the use and access of vast parts of the region, are the reasons why Friuli Venezia Giulia boasts the most biotopes and protected areas in Italy).

3 Military architecture has led to building such unique spaces, buildings and infrastructures that themselves represent possible tourist destinations, both for their architectural traits and for their memories.

The heritage of history and stories, tragic but not only, that a military system can create in a place is a pool to tap into to develop entertainment-cultural trails that can cover vast areas.

These are some of the characteristics inherent to the military world or subconsciously generated by it, which can represent a starting point to develop actual tourist reconversion models.

\subsection{Energy scenario}

Many military sites represented energy sufficient enclaves. The proximity to the electrical supply point, widespread wiring of the site, the presence of electrical 
cabins and large slabs in reinforced concrete are characteristics that make the conversion of many sites into solar parks possible. Out of almost 7.4 million square meters of military sites that we mapped out, nearly 6 million have a good solar exposure. In light of this, energy transformation of Friuli Venezia Giulia applied to abandoned military property becomes an actual strategic plan.

\subsection{Social-housing scenario}

For logistics and mobilisation reasons, many military sites are directly linked or close to the main infrastructures on wheels or rails. From this standpoint, by implementing such infrastructures with bypasses, a reconversion is possible into highly developed residential parks, even far from the main urban centres, since they are served by fast motorways and railroad connections.

\section{Conclusions}

The project A Farewell to Arms has been presented to the main regional institutions and organisations, generating unanimous interest and gaining complete agreement. The regional administration has expressed its intention to adopt it in its urban planning, but the political dynamics and the current economic situation have slowed down a lot this potential development.

Some tourism scenarios have been adopted by private associations, which are developing and promoting them.

On the other hand, the cultural association Cinemazero, together with the film distributor Tucker Film, after making a video on the state of military disuse in Friuli Venezia Giulia, are producing a documentary film to show the heritage of stories that militarisation has left in the region.

The whole project A Farewell to Arms and its development can be looked up on: www.primulecaserme.

\section{References}

[1] Jean C., Militaria. Tecnologie e strategie, Franco Angeli, 2009.

[2] Ministero della difesa, Commissione IV, Indagine conoscitiva del 25/10/2006. Online. http://www.camera.it/_dati/leg15/lavori/stencomm/04/ indag/militari/2006/1025/s000r.htm

[3] Antonio Rossitto, Caserme dismesse: facciamone ospedali e uffici in Panorama, 29/11/2006. Online http://archivio.panorama.it/home/articolo /idA020001039080

[4] Legislative Decree $n^{\circ} 237$ of 24/04/2001. Online http://www.camera.it /parlam/leggi/deleghe/testi/01237dl.htm

[5] Legislative Decree $\mathrm{n}^{\circ} 35$ of 02/03/2007. Online http://www.camera.it /parlam/leggi/deleghe/testi/07035dl.htm 